\title{
SOLID FILMS AND INTERFACES IN FUSED SALT ELECTROCHEMICAL SYSTEMS
}

\author{
A. J. ARVIA AND N. R. DE TACCONI \\ Instituto de Investigaciones Fisicoquimicas Teóricas y Aplicadas, División Electroquimica, Sucursal 4, \\ Casilla de Correo 16, 1900 La Plata (Argentina) \\ (Reccived June 4, 1976; accepted February 14, 1977)
}

The present review deals with two main aspects of the electrochemical formation and characteristics of thin solid films. The first shows, through a few typical examples, that these films occur at different metal-molten electrolyte interfaces and that their average composition depends on how they are formed, i.e. anodically or cathodically. The second aspect deals with the kinetics of thin film formation. The first reaction, which has undoubtedly been the more thoroughly investigated, involves the early stages in the formation of an oxygen monolayer on platinum in molten alkali bisulphates. The electrochemical features of this interface are also found at other metal-molten electrolyte interfaces. Finally, the kinetics of multilayer thin film electroformation are presented to show that the nucleation and film growth laws derived for film formation at metal-solution interfaces also apply to metal-melt interfaces.

\section{INTRODUCTION}

Most metals when placed in contact with an ionic melt undergo a spontaneous dissolution process which can be assisted by an applied external potential at the metal-electrolyte interface. The result is the formation of an insoluble film which covers the metal surface. Clearly films are formed more easily when the resulting compound has a low solubility product in the ionic melt. The films (either monolayer or multilayer) are bound to the metal surface by either adsorption or chemisorption forces. Therefore film formation implies a definite change of the physicochemical characteristics of the electrochemical interface compared with those of the clean metal surface, and the study of the thin films becomes important both because of their role in the prevention of corrosion of metal in molten salt media, including hot corrosion processes, and because of other valuable practical applications.

The electrochemical formation of thin films involves various important features. For example, from the structural point of view (and in particular if an electrical double layer is considered) a molecular approach to the study of the rate processes is required, but this is beyond the scope of the present review - the interested reader is referred to refs. 1-5.

Another important aspect involves the thermodynamics of the formation of insoluble compounds in each particular ionic system. This type of information is 
usually presented in diagrammatic form involving the equilibrium potential and the logarithm of the ionic activity either of a potential-determining species or of a reacting species ${ }^{6-9}$. The information obtained from these diagrams is useful in establishing the stability region of the possible systems at equilibrium. Complementary thermodynamic data, related in particular to metal slag gas systems. have recently been published ${ }^{10}$. The occurrence of a particular system depends not only on the thermodynamic predictions, including the solubility characteristics of the reaction products, but also on the kinetics of the processes involved.

The kinetics of the electrochemical growth of insoluble films covers a wide range of behaviour which depends on the type of film formed and on the stage of growth at the metal--molten electrolyte interface. The early stages of the electrochemical process may involve the formation of a metal insoluble layer electrolyte interface where the insoluble layer is one monolayer thick. During the monolayer formation the rate-controlling reaction presumably occurs at the metal electrolyte interface, and once the film is continuous the initial reaction ceases.

Another possibility is the electroformation of an insoluble multilayer film. which may involve nucleation and different physical mechanisms of film growth ${ }^{11.12}$. The growth of porous non-protective films is mainly related to transport phenomena in a much more complicated fashion than is the growth of a continuous film of an essentially uniform thick ness.

A third type of film arises from the formation of an imperfect semiconducting oxide film on a metal that is in contact with a molten salt ${ }^{1}$.

The possible types of structure of solid thin films in metals correspond to the structure types of solid electrolytes, and these have recently been summarized in the literature ${ }^{13}$.

The present review is divided into two main parts. The first part covers electrochemical film formation in different metal-molten salt systems. The second part deals particularly with kinetic studies, which have been most extensively made on the early stages of oxygen monolayer formation on platinum in molten alkali bisulphates, and also with some aspects of the kinetics of multilayer growth. The types of processes described herein are of general validity for other metal molten electrolyte interfaces.

\section{THE ELECTROCHEMICAI. FURMATION OF INSOLUBLE IILMS}

\subsection{Alumina film}

Aluminium can be anodically oxidized in low temperature melts ( 100.250 C) of sodium bisulphate, potassium bisulphate or a mixture of both. with the formation of an $\alpha$-alumina (corundum) film. At $1 \mathrm{~A} \mathrm{dm}^{-2}$, a white matt film is produced which is rather porous but very hard and chemically resistant. The film thicknesses are of the order of $10 \mu \mathrm{m}$. The coating ratio of film weight to metal loss is 1.76-1.81, which is nearly equal to the theoretical value 1.89. X-ray diffraction patterns clearly indicate the formation of $\alpha$-alumina with a very slight amount of $\gamma$ alumina ${ }^{14}$. Electron microscope studies of the electrocrystallization of the anodically formed $x$-alumina films have shown that they are of the all-barrier type. Crystals grow directly on the aluminium, and no boundary layers are observed between them. Refractive index measurements of the stripped films have shown that 
an amorphous oxide formed first, and this is immediately transformed to $\gamma$-alumina and finally to $\alpha$-alumina by local heating due to electric arcing.

The oxidation reaction apparently occurs at or near the melt-oxide interface under the anodic potential by the migration of trivalent aluminium ions through lattice imperfections in the oxide ${ }^{15}$.

The anodization of aluminium in (sodium-potassium) nitrate eutectic at $250 \mathrm{C}$ proceeds in several stages, depending on the magnitude of the anodic polarization. The first stage, occurring between 1.2 and $3.8 \mathrm{~V}$ measured from the rest potential, corresponds to the formation of a thin tight barrier-type oxide film. The second stage, at higher potentials and $2 \mathrm{~mA} \mathrm{~cm}^{-2}$, corresponds to the formation of a porous oxide film. During the third stage, with a further increase in current density and voltage, a thickening of the film occurs. The oxide coatings formed in the second and third stages of anodic polarization are characterized by very well-expressed unipolar properties ${ }^{16}$.

The anodization of aluminium in molten potassium nitrate at $450 \mathrm{C}$ yields an alumina film which appears as a structural compound in which crystalline and amorphous phases can be distinguished. The oxides are characterized by low porosity and sealability. The coating ratio depends on the anodizing temperature and in many cases is higher than the theoretical ratio. A series of transition reactions during the anodization process involving the succession $\alpha$-alumina $\rightarrow \gamma$-alumina $\rightarrow$ $\delta$-alumina $\rightarrow \theta$-alumina has been postulated ${ }^{17}$. Both the properties of the anodized film and the coating ratio depend markedly on the anodizing temperature $(300-450 \mathrm{C})$. The current $i$ changes with potential $E$ according to the equation $i=A \exp (B E)$, the kinetic parameter $B$ being $6.64 \times 10^{-5} \mathrm{~cm} \mathrm{~V}^{-1}$ and the activation distance $13.8 \AA^{18}$.

Steady state ionic conduction studies on anodic film growth in (lithium-sodium-potassium) nitrate melt have been performed up to a film breakdown voltage of $73 \mathrm{~V}$. This voltage is independent of the current density or temperature. The film-forming current-potential characteristics involve a Tafel line with a slope which decreases with increasing temperature. This effect has been explained in terms of Dignam's equation for ionic conduction, for which the parameter $\mu^{*}$ depends on temperature but the exchange current density and potential are temperature independent ${ }^{11,19}$.

It has been claimed that non-porous and very pure anodic alumina films are formed in (sodium-potassium) nitrite eutectic ${ }^{20}$. Transparent films are obtained by anodization at voltages below the sparking voltage. Their formation proceeds according to the usual kinetics of non-porous films. An ever-burning spark appears at voltages higher than the sparking voltages and it moves over the electrode surface leaving a white matt track until the film becomes opaque. Both types of films exhibit excellent adherence and high corrosion resistance. The melt possesses a strong tendency to form films.

\subsection{Copper oxide films}

A thin film of cuprous oxide is formed when copper is immersed in (lithium-potassium) chloride eutectic containing oxide ions, in the temperature range $400-500 \mathrm{C}$ and at oxide ion concentrations in the range $0.1-0.2 \mathrm{M}$. The corresponding interface, copper-cuprous oxide-oxide ion, behaves as a second- 
class reversible electrode 21 . The solubility of the copper oxide is relatively high, a fact which limits the application of the electrode in the evaluation of oxide ion concentration in these mels to concentrations ${ }^{21}$ of greater than $10^{3} \cdot \mathrm{M}$.

The behaviour of copper in molten (sodium potassium) nitrate at 250 C. deduced from electrode potential measurements and X-ray analysis, indicates that films formed on copper consist mainly of cuprous oxide ${ }^{22}$. The passivity of copper in the (sodium potassium) nitrate melt at 300 C has been attributed to a protective film of cupric oxide 23.24 .

The copper:oxygen atomic ratio of the tilm formed depends on the anodization conditions and temperature. although the potential limits related to the stability of either cuprous or cupric oxide can be established through potential p(oxide ion) diagrams ${ }^{25}$. The electrochemical behaviour of copper in molten alkaline nitrites is very similar to that observed in molten nitrates ${ }^{20}$.

When copper is cathodized in molten sodium nitrate a vellow precipitate. corresponding to the empirical formula $\mathrm{Na}_{2} \mathrm{O} \cdot \mathrm{Cu}_{2} \mathrm{O} \cdot \mathrm{H}_{2} \mathrm{O}$. is formed initially and is then oxidized either by species present in the melt or by atr. If sufficient sodium peroxide is added to the melt. the precipitate partially dissolves to form an orange red solution which on freezing yields a green solid ${ }^{2-}$.

The anodic oxidation of copper in molten sodium tetraborate results in the formation of cuprous oxide solid film if either the divalent copper ion concentration in the melt or the current density is increased ${ }^{2 x}$.

\subsection{Oxide films of the iron group metals}

Oxide films on the iron group metals are formed in various melts containing oxo anions such as sulphate, bisulphate nitrate and carbonate ${ }^{29}+2$. These oxide films are formed either spontaneously when the electropolished metal contats the molten salt or when the metal is anodized in the melt. The spontaneous formation is accompanied by an increase in the potential at the metal fused salt interface.

The diffractogram of an iron sample spontancously passivated after 12 h of immersion in (sodium potassium) nitrite at 243 C shows well-defined peaks which correspond to the metal and magnetite respectively ${ }^{+3,+4}$. A diffractogram of an iron electrode which has been previously potentiostatically anodized at 0.2 V for $2.5 \mathrm{~h}$ exhibits these same features although the height ratio of the magnetite peak to the metal peak is greater. indicating the formation of a thicker film in the anodically treated iron.

The film responsible for passivity in either molten nitrates or molten nitrites requires a thickness of several layers, as has been deduced from the area of the corresponding current peak obtained in voltammetric current potential curves ${ }^{55}$. The predominant structure of the thicker passivating films obtained at low anodic potential corresponds to magnetite with traces of ferrous oxide. At higher anodic potentials the oxide film approaches the ferric oxide structure. No definite potential region can be assigned to the composition change of the film which apparenty oceurs at potentials between the passivity potential and the potential for the breakdown of passivity.

The electrochemical formation of the various oxides of the iron family metals in molten nitrates and nitrites has been correlated with different potential proxide ion) diagrams ${ }^{46}$ t8 
A protective film of magnetite and spinel is formed on iron in (lithium-sodium-potassium) carbonate melts at $500-700{ }^{\circ} \mathrm{C}$ under carbon dioxide, argon and carbon dioxide + oxygen $(2: 1)$ atmospheres. The substitution of carbon dioxide for argon at $500-600^{\circ} \mathrm{C}$ accelerates the formation of the oxide film. Its composition changes at $700^{\circ} \mathrm{C}$, accompanied by a decrease in its passivation properties $^{49}$.

The passivating films formed ${ }^{50}$ on iron in borate melts at $900 \mathrm{C}$ consist of layers of mixed iron oxides. The potentials at which the individual oxides are formed have been determined. Two passivation regions have been found, one caused by the formation of magnetic layers and another related to the formation of a ferric oxide layer $^{51}$.

Iron passivation in alkaline carbonate melts at $600 \mathrm{C}$ involves a thick layer $(30$ $\mu \mathrm{m})$ of the spinel $\left(\mathrm{LiFeO}_{2}\right)$ and magnetite types of coating compounds. These layers are able to protect the metal in carbonate melts ${ }^{52}$.

A nickel electrode in (lithium-potassium) chloride eutectic containing oxide ions at $400-500^{\circ} \mathrm{C}$ forms a nickel-nickel oxide-oxide interface which shows irreversible behaviour ${ }^{21}$.

A nickel electrode attains a passive state in a nitrite melt even when there is no net current flow through the external circuit. This phenomenon is undoubtedly related to a nickel oxide film, probably having the NiO lattice structure. No evidence has been obtained to indicate the existence of a nickel oxidation state higher than divalent nickel. The average thickness of the passive film is ${ }^{48} 10 \AA$. The oxygen : nickel atomic ratio can then be increased above unity by the penetration of adsorbed atoms.

Nickel undergoes spontaneous passivation in a nitrate melt ${ }^{29-41}$ at $400-500^{\circ} \mathrm{C}$, as is revealed by the continuous shift of the electrode potential from its value on immersion to more positive values. It has been confirmed that the film which characterizes the passive region also corresponds to an $\mathrm{NiO}$ lattice structure $^{53}$. The average thickness of nickel oxide involved at the onset of passivity according to galvanostatic transients $s^{4-45}$ is again of the order of $10 \AA$ as in alkali nitrite melts. The passivation process takes place much faster than in the nitrite melt, probably because of the higher oxidizing power of molten nitrates. An interpretation for the nickel rest potential in the nitrite melt has been advanced on the basis of nickel oxides of different stoichiometry ${ }^{54}$. Extending this interpretation to the nitrate system it is concluded that the nickel oxide related to the rest potential has on average a composition of $\mathrm{NiO}_{1.36}$.

The passivation of nickel in (lithium-sodium) carbonate, (lithium-potassium) carbonate, (lithium-sodium-potassium) carbonate and lithium carbonate melts at $600-800^{\circ} \mathrm{C}$ is caused by a thin solid film consisting ${ }^{52}$ of either $\mathrm{Li}_{2} \mathrm{O} \cdot \mathrm{NiO}$ or $\mathrm{Na}_{2} \mathrm{O} \cdot \mathrm{NiO}$.

A nickel oxide ( $\mathrm{NiO}$ ) film is also formed on nickel anodes in molten sodium tetraborate at $800-900 \mathrm{C}$ as revealed by $\mathrm{X}$-ray analysis ${ }^{50}$. It grows to a definite thickness of about $35 \AA$, exhibiting the characteristics of a p-type semiconductor ${ }^{55}$.

A NiO film is electrochemically formed on nickel in silicate melts (sodium oxide $40 \%+$ silica $60 \%$ ) at $125 \mathrm{C}$ during polarization in the potential region of oxygen evolution $^{56}$.

On electro-oxidation ${ }^{57}$ of cobalt in molten alkali nitrate melts at $250 \mathrm{C}$, the 
metal becomes covered with a $\mathrm{CO}_{3} \mathrm{O}_{4}$ film. The same film is formed atter immersion of the metal in the melt.

The passivation of cobalt in molten tetraborate at 900 ( imvolves 2 the $^{2}$ formation of a semiconductive $C$ OO film of $50100 \mathrm{~A}$. At high anodic potentials the film thickness increases $103000 \AA$. apparently approaching the non-stoichiometric structure $\mathrm{COO}_{1},(x>0)$. The electrochemical cvolution of oxygen takes place as soon as a critical concentration of excess oxygen atoms in the film is attaned ${ }^{2 k}$.

\subsection{Films on platimam and ofher nohle metals \\ 2.4.1. Hidrogen adatom film}

Studies of hydrogen electrode reactions in jonic melts have indicated that near the equilibrium potential the platinum surface is probably covered to a large extent with hydrogen adatoms ${ }^{58.54}$. Results from recent studiesno have clearly demonstrated that the first stage of hydrogen evolution on platimum dectrodes in molten alkali bisulphate is the formation of a monolaver of hydrogen adatoms. Furthermore. this monolayer can be yuantitatively clectro-oxidized in the same potential region in which the intial electro-reduction process look place. When both the cathodic and the anodic process proceed potentiodynamically, the current potential curve exhibits at least two well-defined current peaks for each process which can be interpreted in terms of at least two different interactions between the hydrogen adatoms and the metal sites. To a first approximation, in (sodium potassium) bisulphate melt at 186 ( the numbers of sites for weakly bound and for strongly bound hydrogen adatoms on platinum are nearly the same. The free energy difference ${ }^{6 !}$ between these states, as derived from the potential difference of the anodic current peaks, is about $6 \mathrm{kcal} \mathrm{mol}$ '. In spite of very different cemperatures and solvent systems the platinum hydrogen sodium polassium) bisulphate melt interface exhibits a behaviour very similar to that of aqueous systems 2 . The different platinum hydrogen surface bond energies can be interpreted in terms of lattice structure and possible atom accommodation on the metal surface ${ }^{\text {t.3. }}$.

\subsubsection{Oxigen-containing films}

The fact that platinum immersed in fused electrolytes such as molten oxides and slags at high temperatures is a useful reference electrode is probably related to the reversibility of the platinum platinum oxide oxide ion interface ${ }^{\text {th. }}$.5. Thus the metal metal oxide interface at high temperature can be considered in terms of conventional electrical equivalent circuits. By using this concept. different relaxation techniques have been applied to study the platinum slag interface ${ }^{\text {in }}$.

Platinum is passivated by the formation of a protective film in fused chloride salts ${ }^{67}$. 9 . The formation of a chloride film takes place at low concentrations of oxide ions, but an oxide film oceurs in moreconcentrated melts. The thickness of the passivation film is several hundred atomic layers. and the matrix is fairly loose. The addition of oxide ions to the (lithium potassium) chloride eutectic at 430 C passivates the platinum surface by the formation of a protective oxide film. The basic electrochemical properties of the film formed are similar to those reported for the same metal in bisulphate melts ${ }^{-11} ? 3$.

In deoxygenated molten chloride media. the electrochemical passivation of 
platinum is related ${ }^{53.57}$ to a precipitation of a compound with the formula $\mathrm{K}_{2} \mathrm{PtCl}_{6}$.

Oxide layers can also be formed on platinum anodes and platinum cathodes in molten lithium, sodium and potassium nitrates individually ${ }^{75}$. The area of the anode that is covered by oxygen atoms increases with the polarization potential and with time although it reaches a limiting value of about 2.6 oxygen atoms per apparent surface platinum atom. No cation effect on the anodic formation of the oxide films has been observed ${ }^{76}$. The cathodic reaction involves thick multilayer oxide formation with a growth rate that depends on the cation present in the melt ${ }^{76}$.

\subsubsection{Sulphur-containing films}

The electrochemical behaviour of pure molten potassium thiocyanate has been studied in the temperature range $150-325^{\circ} \mathrm{C}$ in order to develop electrolyte systems that can be used in high energy density thermal batteries ${ }^{77.78}$. A film growth occurs on platinum when the metal is anodized in the melt ${ }^{79}$ at $190^{\circ} \mathrm{C}$. The anodic discharge of thiocyanate ions at low anodic potentials yields the thiocyanate radical $\mathrm{SCN}$ which, through the dimer $(\mathrm{SCN})_{2}$, undergoes polymerization to parathiocyanogen $(\mathrm{SCN})_{x}$, a yellow-orange solid that is insoluble in most solvents. The film remains unaltered only for a relatively short time, allowing the study of the kinetics of its electroformation and electrodissolution by the application of different relaxation techniques ${ }^{79,80}$. At the temperature of the melt the solid film undergoes chemical decomposition into sulphur and dicyanogen $(\mathrm{CN})_{2}$ after a relatively long time ${ }^{81.82}$. Two main processes can be distinguished at anodic potentials. The initial process corresponds to a uniform coverage of the surface by the reaction product, and the process that follows is the thickening of the passivating film. The rate of the initial process at constant potential is apparently determined by the peripheral area of the growing patches as described in Section 3.

Sulphide films $\left(\mathrm{Na}_{2} \mathrm{~S}_{2}\right)$ can apparently be formed on vitreous carbon cathodes when sodium polysulphide melts are electrolysed ${ }^{83}$ in the temperature range $300-400^{\circ} \mathrm{C}$. Metal sulphides and metal oxide can also be produced during the electro-reduction of (lithium-sodium-potassium) sulphate melts ${ }^{31}$ at $550^{\circ} \mathrm{C}$.

\subsection{Other anodic films electrochemically formed in ionic melts}

Palladium and bismuth in (lithium-potassium) chloride eutectic at $400-500^{\circ} \mathrm{C}$ also form thin films in the presence of oxide ions (0.1-0.2 M). Palladium forms a palladium-palladium oxide $\mathrm{PdO}$-oxide interface, while bismuth yields a bismuth-bismuth oxychloride $\mathrm{BiOCl}$-oxide interface; both these systems behave as reversible electrodes of the second kind ${ }^{21}$.

Aluminium carbide formation can take place in molten alkali metal chlorides containing aluminium trichloride when aluminium is electrodeposited on a carbon electrode at $620^{\circ} \mathrm{C}$. X-ray analysis has shown that the film consists of species ${ }^{84}$ having the formula $\mathrm{Al}_{4} \mathrm{C}_{3}$ and $\mathrm{Al}_{4} \mathrm{O}_{4} \mathrm{C}$. The rate of formation obeys the parabolic rate law.

On the anodization of zirconium in (lithium - potassium) chloride eutectic at 400 and $500{ }^{\circ} \mathrm{C}$ a plateau has been observed which is attributed to the formation of a layer of insoluble zirconium dichloride which disproportionates at temperatures higher than $550^{\circ} \mathrm{C}$, yielding zirconium and zirconium tetrachloride ${ }^{85}$. 
An insoluble zirconium trichloride film can also be formed during the electro-reduction ${ }^{86}$ of either zirconium tetrachloride or $\mathrm{Na}_{2} \mathrm{ZrCl}_{6}$ in fused (aluminium sodium) chloride (5I $52 \mathrm{~mol} . "$ "aluminium trichloride) at $175200 \mathrm{C}$.

Uranium dioxide hemispherical deposits have been obtained ${ }^{87}$ on a platinum cathode tip in (lithium potassium uranyl) chloride melt at $400 \mathrm{C}$

Carbon and graphite anodes (often used in halide-containing molten salt systems) usually become covered with a film of the $\mathrm{CX}$ 1ype, where $\mathrm{X}$ is a halogen atom such as chlorine or fluorine 88 " These surface compounds exhibit electroinsulating properties which probably render the electrode less wettable by the electrolyte.

Anodic oxide films have been formed on titanium in fused (sodium cobalt) nitrate at 300 C. The metal had been treated with $30^{\circ}$ "nitric acid, which produced a polycrystalline (octahedral) film with a small amount of rutile intrusions"3. The anodization of the film yields the rutile structure because the oxidation proceeds primarily by oxide ion movement.

On the anodic oxidation of tantalum in molten (lithium, sodium, potassium) nitrate electrolytes an oxide film is formed on the metal; its growth is accounted for satisfactorily by Dewald's double-barrier theory. The kinetics are independent of the electrolyte used ${ }^{44}$.

Cadmium electrodes in molten nitrate melts exhibit a chronopotentiometric wave at high cathodic voltages; this has been ascribed to the reduction of the surface cadmium oxide layer spontaneously formed in the melt ${ }^{95}$.

A protective film is also formed on tungsten; this is assumed to be either potassium tungstate or sodium tungstate $e^{8-4}$.

\subsection{Cathodic film formation}

The electro-reduction of potassium chromate in molten (lithium potassium) chloride in the presence of divalent magnesium ions shifts the well-characterized electrode potential of chromate reduction by $0.9 \mathrm{~V}$, yielding a highly insoluble chemically resistant electrodeposit at the cathode; this deposit has been identified as a single non-stoichiometric compound of empirical formula $\mathrm{Li}_{x} \mathrm{Mg}_{3} \mathrm{CrO}_{4}$, where $x+2 y=5$. and $x$ and $y$ depend on the electrolysis conditions ${ }^{46}$.

The electro-reduction of chromate on platinum in chloride melts containing either nickel chloride ${ }^{97}$ or zinc chloride ${ }^{98}$ at 450 and 300 C respectively yields insoluble electrodeposits. For a melt containing nickel chloride ${ }^{97}$ the stoichiometry of the deposit depends mainly on the temperature at which it is formed. At $500 \mathrm{C}$ the composition approaches the formula $\mathrm{LiNi}_{2} \mathrm{CrO}_{4}$, corresponding to a single compound with an f.c.c. lattice. In a melt containing zinc chloride the deposit appears to be a non-stoichiometric compound of the general form $\mathrm{K}_{x} \mathrm{Zn}_{1} \mathrm{CrO}_{2}$ where $x, y$ and $z$ depend upon the conditions of the electrolysis ${ }^{98}$. In the melts containing lithium ions the insoluble reduction product corresponds ${ }^{99}$ to $\mathrm{LiZn}_{2} \mathrm{CrO}_{4}$. The same process in the presence of cobalt(II) chloride yields ${ }^{99}$ $\mathrm{CO}_{2} \mathrm{CrO}_{4}$ at low cathodic potentials and high cobalt(II) ion concentrations and $\mathrm{LiCO}_{2} \mathrm{CrO}_{4}$ at high cathodic potentials and low cobalt(II) ion concentrations.

The irreversible electro-reduction of the nitrate ion in molten nitrates is limited by the precipitation of alkali metal oxides at the electrode surfaces ${ }^{42.100}$. 


\section{KINETIC ASPECTS}

\subsection{Oxide monolayer electroformation and electrodissolution at platinum-melt interfaces}

Oxide monolayers, either adsorbed or chemisorbed, can be electroformed on platinum electrodes in molten alkaline bisulphate under various experimental conditions ${ }^{70-73}$. The kinetics of these processes, particularly the early stages, can be followed by means of potentiodynamic methods. Two basic experimental techniques, the linear potential sweep (as either a single or a triangular potential sweep $^{101}$ ) and the triangularly modulated linear potential scan ${ }^{102}$, give not only qualitative information but also a reasonable amount of quantitative data.

The oxygen monolayer formation and its electro-reduction occur in the potential range between $0.2 \mathrm{~V}$ and $0.6 \mathrm{~V}$. measured against the hydrogen reference electrode in potassium bisulphate melt. Thus, under a triangular potential sweep between these potential limits, the current-potential (time) display exhibits, apart from double-layer charging and discharging, an anodic current region with a current maximum corresponding to the formation of the oxygen monolayer and a cathodic current region also with its own current maximum corresponding to surface oxygen electro-reduction ${ }^{72.73}$. It should be emphasized that, in spite of the very different temperatures and solvent systems, the platinum-potassium bisulphate melt interface is very similar in behaviour to the aqueous acid systems ${ }^{62}$.

The current-potential profile presents a broad anodic current peak and a narrow more symmetric cathodic current peak. The potential of the anodic current peak is always more positive than that of the cathodic current peak, and both depend on the rate of the potential perturbation. The amount of charge related to the oxygen monolayer can be obtained by integration of the current-potential (time) curves. The roughness factor of the platinum electrode can be determined by the amount of charge involved in the anodic reduction (hydrogen) current peaks ${ }^{103.104}$. The ratio of anodic charge to cathodic charge approaches unity as the rate of the potential scan increases.

It has been observed that the anodically formed monolayer suffers an aging process which, although the platinum:oxygen atom ratio remains unchanged, is clearly manifested by the current-potential curves related to its electro-reduction. Thus electro-reduction of the aged oxide shows the highest degree of symmetry of the cathodic current peak; simple linear relationships can then be obtained between the cathodic current peak height and the potential sweep rate and between the cathodic current peak potential and the logarithm of the potential sweep rate. Under these circumstances the initial portions of the cathodic current-potential curves are coincident whatever the perturbation conditions ${ }^{71,72}$. The electroreduction of the aged oxide takes place with an appreciable degree of irreversibility $^{71}$. The aging process is also involved during oxide electroformation as a parallel reaction ${ }^{105}$. The electrochemical reduction of the surface oxygencontaining species apparently becomes more reversible as the temperature increases $^{72}$.

However, the current-potential curves obtained with triangularly modulated linear potential sweeps reveal the formation of a short-life species whose half-life at $223 \mathrm{C}$ has been estimated ${ }^{72}$ to be of the order of $10^{-3} \mathrm{~s}$. This reaction intermediate 
is associated with a reversible redox couple which is clearly formed when the amount of charge involved at the surface is only a fraction of a monolayer.

The kinetic results reveal that the controlling process occurring during clectrooxidation or during electro-reduction is confined to the metal electrolyte interface. The overall processes, either anodic or cathodic. involve charge transfer steps. chemical reactions, yielding different intermediates and including the formation of aged species, and eventually chemical dissolution of the oxygen-containing film. The kinetic data that have recently been reported indicate that in principle at least two different species participate in the overall electrode reactions $105,100$.

The initial species formed during the electro-oxidation process behaves more reversibly than the intermediate species that follows. and the rate of any reaction corresponding to a change from the initial intermediate to the second species is slower than the rate of reaction of the redox couple involving the initial anodic product. The reaction mechanism recently proposed ${ }^{105.100}$ comprises consecutive and alternative steps which are envisaged as follows. The anodic process is given by

$$
\mathrm{Pt}_{1}+\mathrm{H}_{2} \mathrm{O} \stackrel{c}{\longrightarrow} \mathrm{Pt}_{y}(\mathrm{OH})^{*} \stackrel{\leftrightarrow \cdot \cdot}{\longrightarrow} \mathrm{Pt}_{p}(\mathrm{O})_{q}^{*} \longrightarrow \mathrm{Pt}_{p}(\mathrm{Ol})_{q}
$$

It implies the electrochemical formation of the $\mathrm{Pt}(\mathrm{OH})$ species, which transforms into the $\mathrm{Pt}(\mathrm{O})^{*}$ species either through an electron transfer step (e) or through electron transfer and a chemical reaction (c) both acting simultancously: finally there is a chemical transformation of $\mathrm{Pt}(\mathrm{O})^{*}$ into a more stable state $\mathrm{Pt}(\mathrm{O})$ which identifies the aged oxide species. During the overall process. at any time $x+y+p=1,0 \leqslant z p \leqslant 1.0 \leqslant p(q \leqslant 1$. The overall reaction involves at least four different sites on the electrode surface. $i . e$. the bare metal surface, the sites covered by $(\mathrm{OH})^{*}$ and those covered by the $(\mathrm{O})^{*}$ and $(\mathrm{O})$ species respectively.

The cathodic reaction (aged) is

$$
\mathrm{Pt}_{p} \mathrm{O}_{4} \stackrel{u}{\longrightarrow} \mathrm{Pt}_{p}(\mathrm{OH})_{l} \longrightarrow \mathrm{Pt}_{m}+\mathrm{H}_{2} \mathrm{O}
$$

The electro-reduction of the aged species involves an electrochemical step yielding a stable $\mathrm{Pt}(\mathrm{OH})$ surface compound, followed by a chemical step which gives the bare platinum surface. The cathodic reaction (unaged) is

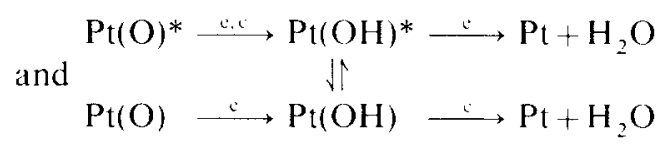

The cathodic reduction of the unaged species is simply the reverse of the anodic process and, depending on the amount of aged species formed, there is a parallel contribution from the cathodic process of the aged surface. Most of the experimental data are in reasonably good agreement with the reaction mechanism just described ${ }^{105.106}$.

The proposed reaction model becomes more general in character since not only does it explain both the anodic and the cathodic potentiodynamic processes related to the platinum - platinum oxide-potassium bisulphate melt interface but it also helps us to understand the potentiodynamic behaviour of similar processes taking place at the iridium-iridium oxide-potassium bisulphate interface ${ }^{10-}$ and at the 
various noble metal-aqueous acid interfaces that have been studied by many authors in the last 30 years ${ }^{62}$.

It is worthwhile, however, to note that in spite of the good agreement between theory and experiment the reaction model involves some crude assumptions. It is more realistic that any surface reaction that yields a monolayer thickness of film under potentiodynamic conditions should be represented in terms of a communal interacting system changing from $\theta=0$ to $\theta=1$, where given values of the metal:oxygen atom ratio must coincide with the stoichiometry of isolated oxide molecules ${ }^{101.108-111}$. From this point of view, the aged species can be imagined as resulting from a re-accommodation of adsorbed species that acquire a more compact structure either through an exchange mechanism between the metal and oxide ions in the solid (where there is a penetration of oxide ions into the metal lattice) or through a distortion of the first crystallographic planes of the metal lattice.

The kinetics of $\mathrm{PtO}$ formation and dissolution in fused (lithium-potassium) chloride eutectic with added oxide ions at $450{ }^{\circ} \mathrm{C}$ has recently been interpreted ${ }^{67}$ using various mechanisms based upon thermodynamic predictions and potentiodynamic current-potential curves for different experimental conditions. The reported dissociation values of the constant for platinum(II) oxide are $1.2 \times 10^{-8}$ (ref. 21) and $3 \times 10^{-4}$ (ref. 67). The decomposition temperature of platinum(II) oxide is not well established, the literature values being 430 and $560^{\circ} \mathrm{C}$ (refs. 112 , 113). Since oxide formation has been observed ${ }^{67}$ at $525^{\circ} \mathrm{C}$, the more likely reaction pathway implies that the platinum oxide is thermodynamically stable at that temperature and that the passivation potential fits the Nernst equation in the potential- $p$ (oxide ion) diagram. However, this is not satisfied because the lithium oxide solution, in which the oxide is considered to be completely dissociated, does not act as a buffer. Accordingly, oxide ion concentrations of less than $10^{-4} \mathrm{M}$ are insufficient to cover the electrode surface. Within the oxide ion concentration range $10^{-5}-10^{-4} \mathrm{M}$ the passivation is due to the simultaneous formation of oxide and chloride.

\subsection{Parathiocyanogen multilayer electroformation and electrodissolution}

The electroformation of a multilayer thin film entails a different type of kinetic behaviour. Film growth involves nucleation followed by a film growth process. The different kinetic possibilities arising for these processes are given in various reviews ${ }^{114-116}$.

The kinetics of parathiocyanogen film formation on platinum in molten potassium thiocyanate is probably one of the reactions that has been studied most thoroughly using potentiostatic transients (either potentiostatic pulses or linear potential sweep techniques) ${ }^{79.80}$. The film behaves as a non-conductor for the anodic current, although it exhibits a Faradaic rectification effect which depends on the a.c. frequency and amplitude. These current-time transients are related to the mechanism of film growth. The metal surface acts only as the initial reaction surface, and the potential response of the anode agrees with the model of film growth with constant thickness control. Thus the current-time curve exhibits a current maximum. The time required to reach the current maximum decreases and the height of the maximum increases when the magnitude of the potential pulse 
increases. The amount of charge related to the film growth process is about 101.3 $\mathrm{mC} \mathrm{cm}{ }^{2}$ which corresponds to a film thickness of $3.0 \times 10^{\circ} \mathrm{cm}$. A linear relationship between the logarithm of the current density on the faces of the growing nuclei and the potential applied to the interface has been observed: the slope of this approaches the value $R T F$ where $R$ is the universal gas constant. $T$ is the absolute temperature and $F$ is the Faraday. This suggests that the kinetics of nuclei growth for a polymeric film are analogous 10 the kinetics observed for the growth of anodic oxides ${ }^{1+}$. The electroformation of the thin film can be represented by the following series of reactions:

$$
\begin{aligned}
& \mathrm{Pt}+\mathrm{SCN}=\operatorname{Pt}(\mathrm{SCN})+\mathrm{e} \\
& \operatorname{Pt}(\mathrm{SCN})+\mathrm{P}^{*}=\mathrm{Pt}^{*}(\mathrm{SCN})+\mathrm{Pt} \\
& \vdots \\
& \mathrm{P}_{1}^{*}(\mathrm{SCN})_{x}+\operatorname{Pt}(\mathrm{SCN})=\mathrm{Pt}^{*}\left(\mathrm{SCN}_{3}\right)_{1}+\mathrm{Pt}
\end{aligned}
$$

Steps (1) and (2) correspond to clementary initial reactions. Pl* representing a nucleation centre. The occurrence of steps (1) and (2) depends on the extent of the electrode coverage. This explanation, however, is probably even more complex because of the possible contribution of diffusion-controlled processes during the film growth. The latter possibility is now being considered ${ }^{1}$ ?

The electro-reduction of the film implies a chemical and mechanical film detachment out of the surface acting simultaneously. Thus the initial process can be represented as follows:

$$
\begin{aligned}
& (\mathrm{SCN})_{x}+\mathrm{e}=(\mathrm{SCN})_{x}=(\mathrm{SCN})_{x+1}+(\mathrm{SCN}) \\
& (\mathrm{SCN})_{x-1}+\mathrm{e}=\mathrm{SCN}+(\mathrm{SCN})_{x}
\end{aligned}
$$

and

$$
(\mathrm{SCN})_{x}+2 \mathrm{e}=(\mathrm{SCN})_{x}{ }^{3-}=\mathrm{S}^{2}+\left(\mathrm{CN}+(\mathrm{SCN})_{x}\right.
$$

The three species, i.e. thiocyanate, sulphide and cyanide ions, have been delected as products of the electrochemical film reduction. Owing to the nature of the film the cathodic reaction mainly proceeds at the metal-film interface instead of at the film-electrolyte interface as generally occurs during the electroformation process. Therefore it is reasonable that, if the potential is at the cathodic side of the potential of zero charge, a type of charge repulsion will produce a detachment of the film out of the surface.

\section{CONCLUSIONS}

The occurrence of different yypes of thin film formation at metal molten electrolyte interfaces is quite general; the formation either is spontaneous through an initial corrosion process or occurs on application of an applied potential. It can be predicted when thermodynamic data are available.

In spite of the scarce quantitative information about the kinetics and mechanisms of these processes, they can in principle be interpreted analogously to those occurring at lower temperatures in the presence of a polar solvent. from the point of view of either monolayers or multilayers. 
The study of the properties of thin films in melts must be encouraged because of their applications in improving the stability of materials at high temperatures, in developing energy storage or energy converter devices and in directing the electrocatalytic properties of electrodes in ionic melts for the production of new substances.

\section{ACKNOWLEDGMENTS}

The Institute (I.N.I.F.T.A.) is patronized by the following institutions: Universidad Nacional de La Plata, Consejo Nacional de Investigaciones Cientificas y Técnicas and Comisión de Investigaciones Cientificas (Provincia de Buenos Aires). This work is partially supported by the Regional Program for the Scientific and Technological Development of the American State Organization.

\section{REFERENCES}

1 G. Morand and J. Hladik, Electrochimie des Sels Fondus, Vol. II, Masson, Paris, 1969, Chap. 1.

2 A. D. Graves, G. J. Hills and D. Inman, Adv. Electrochem. Electrochem. Eng., 4 (1966) 117.

3 S. M. Ahmed, in J. W. Diggle (ed.), Oxides and Oxide Films, Vol. 1, Marcel Dekker, New York, 1972, p. 319.

4 J. Lyklema, Croat. Chem. Acta, 43 (1971) 249.

5 A. I. Sotnikov, O. A. Esin and G. A. Toporishchev. Tezisy Dokl. Vses. Soveshch. Elektrokhim. 5 th. I (1974) 304; Chem. Abstr. 83 (1975) No. 209680.

6 R. Littlewood, J. Electrochem. Soc., 109 (1962) 525.

7 D. Inman and N. S. Wrench, Br. Corros. J., I (1966) 246.

8 J. A. A. Ketelaar, Chem.-Ing.-Tech., 45 (1973) 667.

9 M. D. Ingram and G. J. Janz, Electrochim. Acta, 10 (1965) 786.

10 Z. A. Foroulis and W. W. Smeltzer (eds.), Metal-Slag-Gas Reactions and Processes, The Electrochemical Society, Princeton, N.J., 1975.

11 J. W. Diggle (ed.), Oxides and Oxide Films, Vol. 1, Marcel Dekker, New York, 1972.

12 J. A. Harrison and H. R. Thirsk, in A. J. Bard (ed.), Electroanalytic Chemistry, Vol. 5, Marcel Dekker, New York, 1970, p. 68.

13 W. L. Worrell, in Z. A. Foroulis and W. W. Smeltzer (eds.), Metal-Slag-Gas Reactions and Processes, The Electrochemical Society, Princeton, N.J., 1972, p. 824.

14 S. Tajima, M. Soda, T. Mori and N. Baba, Electrochim. Acta, I (1959) 205.

15 S. Tajima, Y. Tanabe, M. Shimura and T. Mori, Electrochim. Acta, 6 (1962) 127.

16 V. Saifullin and F. F. Faizullin, Sb. Aspir. Rab., Kazan Gos. Univ., Estestv. Nauki, Khim. (1973) 25; Chem. Abstr., 83(1975) No. 185318.

17 L. Campanella, Plating, 59 (1972) 575.

18 L. Campanella, Trans. Inst. Met. Finish., 51 (1973) 97.

19 R. K. Nigam and I. K. Arora, Electrochim. Acta, 17 (1972) 2133.

20 S. Ikonopisov, Electrodeposition Surf. Treat., 2 (1974) 303.

21 H. Laitinen and B. Bathia, J. Electrochem. Soc., 107 (1960) 705.

22 A. Conte, Electrochim. Acta, 11 (1966) 1579.

23 T. Notoya and R. Midorikawa, Denki Kagaku, 41 (1973) 865.

24 T. Notoya, Denki Kagaku, 41 (1973) 779.

25 S. L. Marchiano and A. J. Arvia, An. Assoc. Quim. Argent, in the press.

26 S. L. Marchiano and A. J. Arvia, to be published.

27 R. B. Temple and G. N. Thickett, Aust. J. Chem., 27 (1974) 891.

28 P. I. Buler, G. A. Toporishchev, O. A. Esin, V. B. Lepinskikh and V. A. Kupysov, Zashch. Met., 9 (1973) 724.

29 C. H. Liu, J. Phys. Chem., 66 (1962) 164.

30 G. Bombara, G. Baudo and A. Tamba, Corros. Sci., 8(1968) 393. 


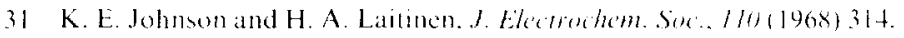

32 G. Baudo and A. Tamba, Br. Corros. J., $4(1969) 129$.

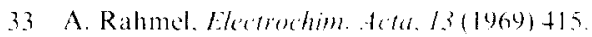

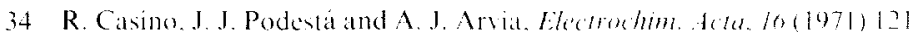

35 B. W. Burrows and (i. J. Hills, Electrohm fith. $15(1970)+45$

36 D. Butinelli. (i. de Gregorio and G. Signorelli. Ria. Si. i/1961)12?

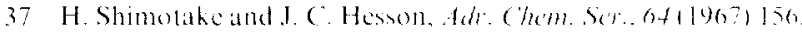

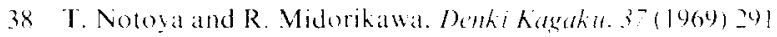

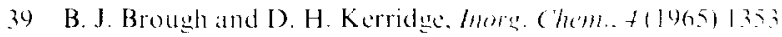

40) F. I. Gurovich, Zh. Pritilad Khim. 2) $(1950) 135 x$

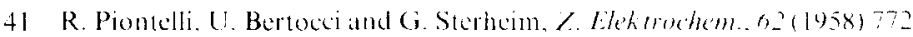

42 H. S. Swofford and H. A. Laitinen. I. Elextrothm. Sin .. I/101963)814.

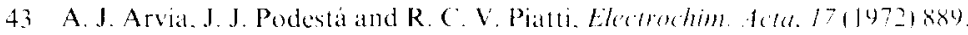

44 A. J. Arvia. J. J. Podestit and R. ('. V. Piatti. Electrochim. tefo. /71972)901.

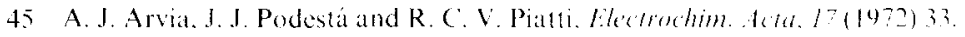

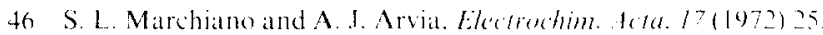

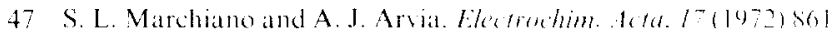

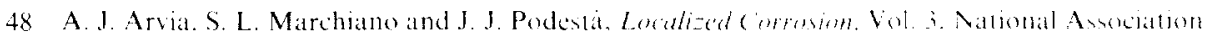
of Corrosion Engincers. Houston. Texas. 197.4. p. 278

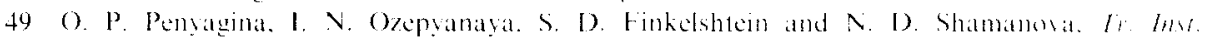

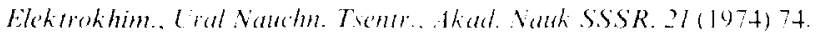

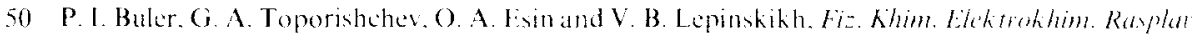

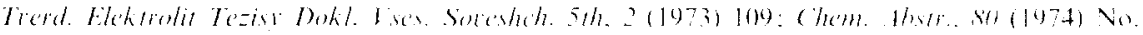
103015

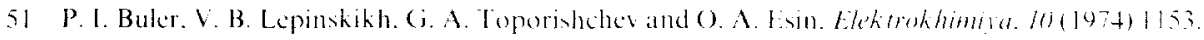

52 O. P. Penyagina. I. N Ozeryanata. M. V. Smirnov. B. S. Shikamovand N D Shamamua /ashh 1/e.. $8(1972) 31$ ?

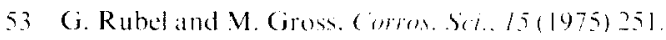

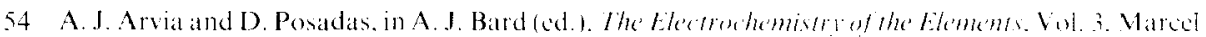
Dekker, New York, 1975. Chap. 3.

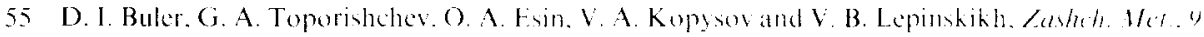
(1973) 196.

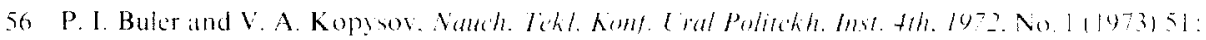
( hom. Ahstr.. so(1974) No. 66009.

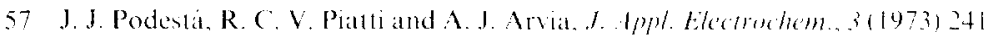

58 H. A. Videla and A. J. Arva. Ekrmoshm. Ach, /6)(1965) 21.

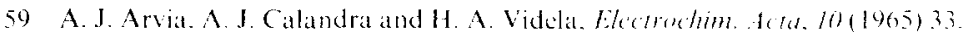

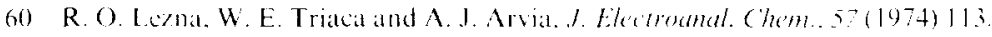

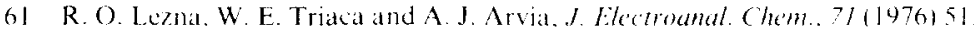

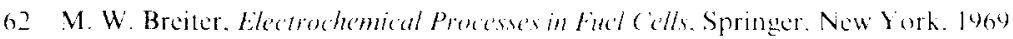

63 H. Angerstein-Kozlowska. H. B. A. Sharp and B. E. Conway. in M. W. Breiter ted.1. Electrocatalive. The Electrochemical Society. Princeton, V.J. 1974. p. 94.

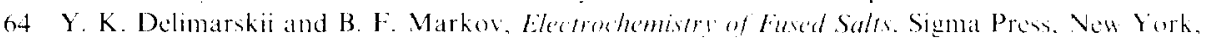
1961.

6.5 W. J. Hamer, J. Elechromat. (hem. I011965) 140.

66) H. Suito, K. Serata and M. Ohtani, in Z. A. Foroulis and W. W. Smeltzer (eds.). Meral Slag Gia Reactions and Processes, The Electrochemical Sociely, Princetom. N.J. 1975. p. 170.

67 M. Takahashi. Y. Katsulama and Y. Kanzaki. I. Electromal. Chem. 6.21975) 36.3

68 D. Inman and M. J. Weaver. I. Electromal. (heme. $5 /(1974)+5$

69 D. Inman. in C. B. Alcock led.). E.MF Heaturements in High Temperature Sistems. I. M. M. Special Publications, London. 1968.

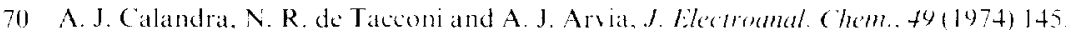

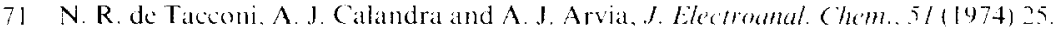

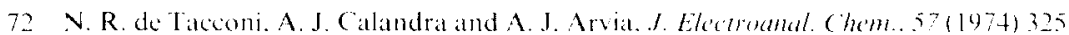

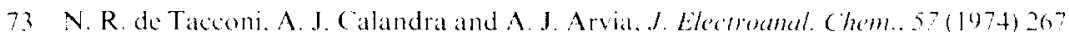

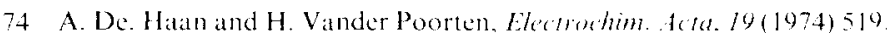


75 R. L. Every and R. L. Grimsley, J. Electroanal. Chem., 9(1965) 167.

76 S. Shibata and M. P. Sumino, Electrochim. Acta. 20 (1975) 871.

77 R. E. Panzer and M. J. Schaer, J. Electrochem. Soc., /12(1965) 1136.

78 K. F. Denning and K. E. Johnson, Electrochim. Acta, /2 (1967) 1391.

79 A. J. Calandra. M. E. Martins and A. J. Arvia, Electrochim. Acta. 16 (1971) 2057.

80 A. J. Arvia, A. J. Calandra and M. E. Martins, Electrochim. Acta, 17 (1972) 741.

81 B. Cleaver, A. J. Davies and D. J. Schiffrin. Electrochim. Acta, 18 (1973) 747.

82 P. Cescon. M. Drago, F. Puciarelli and R. Marassi, J. Electroanal. Chem. 59 (1975) 155.

83 K. D. South. J. L. Sudworth and J. G. Gibson. J. Electrochem. Soc.. 119(1972) 554.

84 T. Narita and R. Midorikawa, Denki Kagaku, 41 (1973) 759.

85 T. N. Grechina, V. T. Barchuk and I. N. Sheiko, Ukr. Khim. Zh., 38 (1972) 656.

86 B. Gilbert. G. Mamantov and K. W. Fung, Inorg. Chem. 14 (1975) 1802.

87 V. V. Puzakov, A. N. Barakoshkin. K. A. Kaliev and K. P. Tarasova, Tr. Inst. Eloktrokhim., Ural Nauch. Tsentr. Akad. Nauk SSSR. 18 (1972) 99.

88 P. Drossbach. J. Electrochem. Soc., 103 (1956) 700.

89 W. E. Triaca, C. Solomons and J. O'M. Bockris, Electrochim. Acta, 13(1964) 1949.

90 A. J. Arvia and J. B. de Cusminsky, Trans. Faraday Soc., 58 (1962) 1019.

91 J. Thonstad, F. Nordmo and K. Vee, Electrochim. Acta, 18 (1973) 27.

92 J. Thonstad, F. Nordmo and K. Rödseth, Electrochim. Acta, I9(1974) 761.

93 I. S. Kotousova. M. N. Dyakonov and S. M. Polyakov, Elektron. Tekh. Nauch. Tekh. Sh. Radiodetali, No. 2(1972) 59; Chem. Abstr., 79 (1973) No. 86693.

94 R. K. Nigam and R. S. Chaudhary. Electrochim. Acta, 17 (1972) 1765.

95 A. Kisza and G. Zakinska, Bull. Acad. Pol. Sci., Ser. Sci. Chim., 20(1972) 719.

96 H. A. Laitinen and R. D. Bankert, Anal. Chem., 39 (1967) 1790.

97 B. Popov and H. A. Laitinen, J. Electrochem. Soc., 117 (1970) 482.

98 M. L. Deanhardt and K. W. Hanck, J. Electrochem. Soc., 122 (1975) 1627.

99 K. W. Hanck and H. A. Laitinen. J. Electrochem. Soc.. 118(1971)1123.

100 M. G. Sustersic, W. E. Triaca and A. J. Arvia. An. Asoc. Quim. Argent.. in the press.

101 A. J. Arvia. An. R. Soc. Esp. Fis. Quim., $7 /$ (1975) 944.

102 B. E. Conway. H. Angerstein-Kozlowska, F. C. Ho, J. Klinger. B. MacDonald and S. Gottesfeld. Discuss. Faraday Soc.. 56 (1973) 210.

103 S. Gilman, J. Electroanal. Chem., 2 (1967) 111.

104 S. Gilman, in A. J. Bard (ed.), Electroanalytical Chemistry, Vol. 2, Marcel Dekker, New York, 1969.

105 A. J. Arvia. N. R. de Tacconi and J. O. Zerbino. Proc. S!mp. on Molten Salts, Washington, D.C., Mar, 1976, The Electrochemical Society, Princeton, N.J., 1976, p. 254.

106 J. O. Zerbino, N. R. de Tacconi, A. J. Calandra and A. J. Arvia, J. Electrochem. Soc., 124 (1977) 475 .

107 J. O. Zerbino. N. R. de Tacconi, A. J. Calandra and A. J. Arvia. J. Electroanal. Chem., 77 (1977) 379.

108 B. E. Conway, L. H. Laliberté. S. Gottesfeld and H. Angerstein-Kozlowska, Proc. Simp. on Oxide-Electrolyte Interfaces, 1973, The Electrochemical Society, Princeton, N.J., 1973.

109 H. Angerstein-Kozlowska, B. E. Conway and W. B. A. Sharp, J. Electroanal. Chem., 43 (1973) 9.

110 B. E. Conway and S. Gottesfeld, J. Chem. Soc., Faraday Trans. I, 69 (1973) 1090.

111 C. Ferro, A. J. Calandra and A. J. Arvia, J. Electroanal. Chem., 65 (1975) 963.

112 L. Wöhler, Z. Elektrochem., 9 (1903) 748.

113 L. Wöhler, Z. Anorg. Chem., 40 (1904) 448.

114 D. A. Vermilyea, Ads. Electrochem. Electrochem. Eng., 3 (1963) 211.

115 J. F. Dewald, in J. O'M. Bockris (ed.), Modern Aspects of Electrochemistr1, Vol. 4. Butterworths, London, 1967. Chap. 3.

116 M. A. Genshaw, in E. Gileadi (ed.). Electrosorption. Plenum Press, New York, 1967, Chap. 4, p. 73.

117 N. R. de Tacconi. A. J. Calandra and A. J. Arvia, J. Electroanal. Chem., in the press. 